A morte da Pedagogia?

\title{
Os fundamentos modernos da educação escolar frente aos desafios da pós-modernidade numa perspectiva histórico-filosófica
}

\author{
The Death of Pedagogy? \\ The Modern Foundations of School Education Facing \\ the Challenges of Postmodernity in a Historical- \\ Philosophical Perspective \\ ¿La muerte de la Pedagogía? \\ Los fundamentos modernos de la educación escolar \\ frente a los desafios de la posmodernidad en una \\ perspectiva histórico-filosófica
}

JoÃo FrANCISCO LOPES DE LIMA (Đa

\begin{abstract}
Resumo
O artigo parte da premissa de que a Pedagogia, enquanto campo teórico-prático, produz diversos enunciados para significar as práticas pedagógicas escolares, desde a Modernidade. Esse legado moderno de formação do "sujeito educado" enfrenta dificuldades nas condições práticas de sua realização, em virtude do cenário pós-moderno que interpela a metafísica, as grandes narrativas, a ideia de unidade e de universalidade, e também a noção de sujeito. Diante do anúncio da morte da metafísica e da morte do sujeito, o pósmoderno representaria também a morte da Pedagogia, já que sucumbem as categorias que lhe são estruturantes. 0 presente estudo, de caráter bibliográfico, sistematiza argumentos para caracterizar esse cenário social e cultural e refletir sobre a possibilidade de a Pedagogia enfrentar o relativismo e a falta de expectativas quanto ao futuro, típicos desse cenário, diante da necessidade de continuar gerando discursos que possam amparar as
\end{abstract}

\footnotetext{
a Universidade do Porto, Porto, Portugal. Doutor em Educação, e-mail: jfrancisco.lima@gmail.com
} 
práticas pedagógicas escolares. A argumentação busca ofertar recursos teóricos a partir de uma leitura não niilista do pós-moderno, e aposta na preservação e renovação, ainda que em bases menos seguras, do potencial pedagógico da tradição moderna como forma de dar sentido às práticas pedagógicas escolares.

Palavras-chave: Pedagogia. Pós-Modernidade. Discurso Pedagógico. Escola. Prática Pedagógica.

\begin{abstract}
The present article is based on the premise that Pedagogy, as a theoretical-practical field, produces several statements to signify pedagogical practices inside schools, since Modernity. The Modern legacy of forming the "educated subject" faces difficulties in the practical conditions of its accomplishment, in the face of the postmodern scenario, that has put in check metaphysics, the great narratives, the idea of unity and universality, and the notion of the individual. Faced with the announcement of the death of metaphysics and the death of the individual, Postmodernism would also represent the death of Pedagogy, since the latter succumbs to the categories that are in its very foundation. The present bibliographical study systematizes arguments to characterize such social and cultural scenario, recognized as postmodern, and to reflect how Pedagogy may face both relativism and the lack of expectations regarding future, typical of this moment, as it is confronted with the need to continue generating speeches that can support school pedagogical practices. The argument seeks to offer theoretical resources from a non-nihilistic perspective of the postmodern, and bets on the preservation and renewal, although on a less secure basis, of the pedagogical potential of the modern tradition, as a way of giving meaning to school pedagogical practices.
\end{abstract}

Keywords: Pedagogy. Post-Modernity. Pedagogical Discourse. School. Pedagogical Practice.

\title{
Resumen
}

El artículo parte de la premisa de que la Pedagogía, como campo teórico-práctico, produce diversos enunciados para significar las prácticas pedagógicas escolares, desde la Modernidad. Este legado Moderno de formación del "sujeto educado" enfrenta dificultades en las condiciones prácticas de su realización, en virtud del escenario posmoderno que interpela la metafísica, las grandes narrativas, la idea de unidad y de universalidad, y también la noción de sujeto. Ante el anuncio de la muerte de la metafísica y de la muerte del sujeto, el posmoderno representaría también la muerte de la Pedagogía, ya que sucumben a las categorías que le son estructurantes. El presente estudio, de carácter bibliográfico, sistematiza argumentos para caracterizar ese escenario social y cultural, reconocido como posmoderno, y reflexionar sobre la posibilidad de que la Pedagogía enfrenta el relativismo y la falta de expectativas en cuanto al futuro, típicos de ese escenario, la necesidad de continuar generando discursos que puedan amparar las prácticas pedagógicas escolares. La argumentación busca ofrecer recursos teóricos a partir de una lectura no niilista del posmoderno, y apuesta por la preservación y renovación, aunque en bases menos seguras, del potencial pedagógico de la tradición moderna como forma de dar sentido a las prácticas pedagógicas escolares. 
Palabras clave: Pedagogia. Post-modernidade. Discurso Pedagógico. Escuela. Práctica Pedagógica.

\section{A Modernidade em questão e o surgimento da pedagogia científica}

A perspectiva que denominamos como Modernidade é herdeira da esperança iluminista de melhoramento do mundo a partir das possibilidades do racionalismo científico e da educabilidade do sujeito. Representa um marco de progresso contra o obscurantismo e a alienação, a partir da condição do esclarecimento do sujeito, da capacidade autônoma de avaliação crítica e do conhecimento objetivo.

A Pedagogia encontra na filosofia iluminista os ideais de progresso humano. Através do cultivo da razão, do acesso à cultura e do que oferece a ciência moderna, pretende obter os meios de sua realização, os elementos para organizar a "didática" necessária à consecução dos fins pretendidos. A partir da Modernidade, e de modo especial a partir do movimento pedagógico da Escola Nova, a Pedagogia emerge como campo científico, uma verdadeira ciência legisladora das questões ligadas à educação escolar.

As teorias da educação "analisam a educação pelo aspecto da sua relação com a sociedade" e uma teoria pedagógica "se estrutura a partir e em função da prática educativa, buscando orientar o processo ensino-aprendizagem" (SAVIANI, 2008, p. 12, grifo meu). A Pedagogia situa-se no campo da teoria pedagógica, nos diz Saviani (2008, 2014, 2015). Isso implica dizer que a Pedagogia opera na interface entre os fundamentos filosóficos, políticos e pedagógicos da educação e os modos de execução prática compatíveis com essa fundamentação, não ficando, portanto, direcionada somente a fins instrumentais. Ao contrário, "se deve encontrar nos fins a atingir a fonte natural para elaborar os métodos e as formas” (SAVIANI, 2015, p. 36). Não há dicotomia entre conteúdo e forma, entre teoria e prática, já que formam, necessariamente, uma unidade dialética.

López (2002) e Lemos (2017) também reforçam o aspecto global da teoria pedagógica, que deve contemplar, em sua organização, diversos suportes. Requer um suporte metateórico que forneça um conjunto de teses filosóficas que informem uma 
concepção de mundo e de função da educação; um suporte teórico-científico que indique as referências teórico-práticas que servirão de recurso para as questões ligadas ao ensino; e, por fim, um suporte tecnológico-aplicativo estabelecido com o fim de normatizar a ação e convertê-la em prática pedagógica. Neste processo interpretativo, um vasto horizonte simbólico permeia e interfere na significação de valores, conceitos e práticas que se pretendam educativas.

\section{A Modernidade e a demarcação de um estatuto pedagógico para a formação do sujeito educado}

Junto com os grandes enunciados, sociais e políticos, os "discursos-mestre" como referiu Lyotard (1998), também os enunciados pedagógicos embalaram as promessas modernas de melhoramento humano e social através do trabalho formativo escolar. A modernidade é capaz de retirar de si mesma seus elementos normativos. Ela fornece a cadeia de valores (perspectiva de ordem, de futuro, de sujeito educado, de civilização) e ao mesmo tempo disponibiliza os meios para tal (a ciência, a lógica e todas as conquistas que o conhecimento racional pode disponibilizar).

Uma importante contribuição para os fundamentos da Pedagogia moderna certamente encontra-se na obra filosófica de Kant (1724-1804). No livro "Sobre a Pedagogia", uma síntese das aulas que Kant ministrou sobre o tema na Universidade de Königsberg, publicado originalmente em 1803, o autor lembra que o homem não poderá ser um verdadeiro homem se não for educado. Reconhece-se nessa abordagem a necessidade de "humanizar" o humano para que ele não sucumba aos seus instintos. Isso implicaria a aquisição de atributos como ser disciplinado, culto, prudente e capaz de ações morais. Para Kant, ser disciplinado impedirá que a animalidade perturbe o caráter; ser culto fornecerá ao sujeito uma habilidade que faculta a seleção e também o alcance dos melhores fins para a vida. Ser prudente será a condição de civilidade própria da vida pública para, por fim, atingir a moralização, ou seja, a capacidade de escolher os bons fins para a sua vida. Para Kant, "bons fins são 
aqueles aprovados necessariamente por todos e que podem ser, ao mesmo tempo, os fins de cada um" (KANT, 1999, p. 26).

A matriz moderna dos sistemas escolares inaugurou a educação institucionalizada como tarefa do Estado e direito dos cidadãos, que poderão superar a condição de súditos através da educação. Com a emergência da escola como uma "instituição educacionalmente especializada" em que "as intenções educativas prévias" somam-se a "estratégias intencionais direcionadas", promove-se a "educação das massas" (COSME; TRINDADE, 2013, p. 10-12) e revela-se como uma grande ocorrência histórica, sublinham os autores.

A escola moderna desenvolve uma pedagogia da instrução coletiva que representa uma otimização dos meios ao "ensinar a muitos como se fosse a um só" (Idem, p. 15) e o ensino simultâneo gerará uma verdadeira "gramática do ensino" (p. 18). A forma escolar da Modernidade funda o "paradigma da instrução", indicam Cosme e Trindade, que é a base de sentido do que ficou convencionado chamar de Escola Tradicional, o modelo de educação escolar do "ensinar tudo a todos" como se fossem um.

Saviani (2015) compreende que nesta forma pedagógica, a pedagogia da instrução, a prioridade está na preparação dos alunos pelo professor, que focará na apresentação da matéria. Esta deverá ser assimilada pelos alunos e, depois de praticada, será generalizada e aplicada. Encontramos como grande ícone da pedagogia da instrução, Johan Herbart (1776-1841). Este autor, que direciona a prática educativa para instruir e moralizar o sujeito humano, servindo-se dos conhecimentos psicológicos. A base do trabalho é dar atenção às representações que formam-se na mente dos alunos a partir das explicações ou demonstrações do professor. Para isso, cabe ao mestre ser eficaz para torná-las o mais claras e completas possível (EBY, 1970).

Da mesma base moderna surgiu a Escola Tradicional e o paradigma da instrução, também surgiu o modelo da Escola Nova no final do século XIX. Esse modelo instalou-se no Brasil no início do século XX, principalmente a partir da década de 1930, com o empenho de Anísio Teixeira e dos chamados "Pioneiros da 
Escola Nova”. Essa vertente surgiu como crítica ao modelo tradicional e inaugurou o “paradigma da aprendizagem” (COSME; TRINDADE, 2013), já que propõe uma ação pedagógica situada na realidade das crianças, nos seus interesses. Trata-se da conversão do método científico em método pedagógico e a inclusão da ideia, ao modo de John Dewey (1859-1952), de que a escola não é o preparo para a vida e, sim, a própria vida.

Para Saviani (2015), a Escola Nova colocou foco na iniciativa dos alunos como ponto de partida da aprendizagem. Concentra-se não na preparação dos alunos pelo professor, mas num problema que desafie a atividade daqueles que partirão em busca de dados, formularão hipóteses e farão experimentações até chegarem à solução do problema de partida. Já estamos no século XXI e parece que a crítica ao modelo dito tradicional de escola não foi suficientemente equacionada pela Escola Nova. Essa perspectiva também não instalou-se de forma soberana, ainda que continue sendo recriada em novas versões até os dias atuais.

\section{A emergência do pós-moderno e seu impacto sobre o discurso pedagógico moderno}

A ideia de pós-modernidade emergiu justamente da constatação de que a lógica do progresso natural da história não se confirmou. O correr desse tempo mostrou-se realizador não apenas das boas promessas da Modernidade. A condição plena do homem ideal prevista pelo humanismo moderno não ocorreu, os modos de vida tradicionais foram pulverizados junto com as noções de família, de autoridade, de ordem e de futuro que os amparava. O poder econômico continuou e continua nas mãos do grande capital. A emergência da voz das minorias e das demandas sociais reprimidas não alterou a ordem política, pelo contrário. Vivemos uma dispersão de valores, ideias e uma quase absoluta relativização de tudo que possa ser apontado como ideal de vida, como ideia de progresso, de futuro da sociedade ou mesmo de fundamento para as ações educacionais. "O futuro já não é o que era”, pondera Boaventura Santos (1997). 
Lyotard (1998) caracterizou o pós-moderno como um verdadeiro estado de incredulidade, uma tal situação social no mundo que, ao modo de Nietzsche (2006), radicalizou a ideia de que não há fatos, não há verdade, não há uma constituição absoluta das coisas, nem há “coisa em si”. Cada pretensão ou vontade de verdade não é mais nem menos do que vontade de poder. Se há uma crença, ela refere-se a um valor, algo que se tem por verdadeiro numa determinada perspectiva.

O culto do novo e do original estão na raiz da Modernidade. Se ela não trouxe todas as respostas e se "o ideal de humanização europeu de humanidade revelou-se como um ideal entre outros", por outro lado, é preciso dizer que a emergência da pósmodernidade "tem um sentido", conclui Vattimo (1992, p. 10). Seria essa uma sociedade não necessariamente mais consciente de si, mas certamente mais complexa", de certo modo "até caótica” (p. 10), porém não necessariamente impedida de buscar formas de emancipação.

Ocorre que a sociedade secularizada contém um tipo de ordem que está em conexão preferencial com o futuro e não com a tradição. A humanidade sempre move-se em função de alguma ideação, de algum tipo de expectativa de devir. Se, como disse Nietzsche (2006), todo o idealismo da humanidade está a ponto de transformar-se em niilismo, em uma crença na absoluta falta de sentido que abarca os modos de vida, a perspectiva de sucumbir ao niilismo é derrotista e fragiliza não apenas o futuro, mas o próprio presente.

Podemos apostar na perspectiva de que a pós-modernidade tem um "sentido" e que pode ser vista como "chance." Isso porque "é precisamente neste relativo 'caos' que residem as nossas esperanças de emancipação" (VATTIMO, 1992, p. 10), o que significaria não sucumbir ao niilismo. Vattimo pensa, no entanto, que não bastará apostarmos na superação da complexidade social somente com os recursos da autoconsciência desenhados por inúmeros autores modernos que vão da ideia de espírito absoluto para Hegel, da consciência revolucionária para Marx ou do sujeito culto e virtuoso, portanto emancipado, ao modo de Kant. São fundamentos importantes, mas não bastam por si neste cenário perturbado em que a contingência dos contextos fragiliza qualquer pretensão de universalidade. 


\section{A morte da Pedagogia?}

Nessa fronteira imprecisa entre abandonar a esperança ou continuar a sonhar sabendo que sonha, como diria Nietzsche (1992), o pós-moderno vem trazer anúncios de morte: a morte das utopias modernas ao denunciar que não podemos mais contar com o conforto das metanarrativas que guardam promessas de redenção como o progresso e a emancipação individual e social; a morte da metafísica a partir da crítica ao absoluto da razão, à ideia de unidade e de identidade do conceito que tem valor por si e não depende de argumentos; por fim, a morte do sujeito, a partir da crítica radical do humanismo moderno e dos seus ideais de perfectibilidade (FARRERO; TORRANO, 2017, p. 283).

Nesse ponto, caberia perguntar: o pós-moderno traria, também, por decorrência, o anúncio da morte da Pedagogia? Para esses autores, essa questão seria plausível pois no cenário pós-moderno a teoria pedagógica "perde a sua dimensão normativa e teleológica", tendo enfraquecida a sua capacidade de continuar a dizer como e por que educar através da escola. Nessa mesma direção, Vilanou et al (2018) afirmam que a pós-modernidade permitiu que possamos dizer que vivemos em uma época pós-filosófica (crise das metanarrativas), pós-histórica (crise dos ideais de superação social — fim da história) e também pós-pedagógica (crise da pedagogia sistemática, normativa). Poderíamos, portanto, inferir que a morte da pedagogia teria ocorrido justamente porque "tornou-se incapaz de estruturar um corpo articulado de acordo com postulados de uma filosofia unitária" (p. 76).

O espírito do humanismo está enlaçado com a tradição pedagógica desde os gregos. Tornou-se matriz fundamental do ideal de sujeito educado na Modernidade, mas há dúvidas importantes se seria ainda possível manter esses valores como a priori pedagógico nesta época pós-moderna e sob quais justificativas. Destaca-se, portanto, uma crítica a um modo de razão que precisa enfrentar o diagnóstico de suas insuficiências e libertar-se dos imperativos da cognição, das finalidades, das utilidades e da moral, nos diz Habermas (2000, p. 126). Trata-se de enfrentar os limites dos modelos explicativos disponíveis e de suas narrativas acerca do sentido da vida, da 
história e também da educação. A sociedade secularizada enfrenta o pós-moderno como um impasse. Se o passado e suas promessas são vistos sob suspeita como um horizonte de expectativas insatisfeitas, logo não há um presente para nos redimir e, portanto, resta que o futuro não teria mais chance.

Para Popoveniuc (2017), impõe-se um relativismo geral, da epistemologia à moral, e faz-se a promoção do subjetivismo pela crítica aos pilares modernos do universalismo e da objetividade. A crítica enfrenta o idealismo moderno e faz, como já indicado, a denúncia dos limites da expectativa do progresso da sociedade e da humanidade. Não há garantias para a dialética do esclarecimento e diante do imperativo social de uma visão pluralista, nenhum discurso pode reivindicar prioridade sobre os demais. No cenário pós-moderno, a educação precisaria ajudar os alunos a construir valores diferentes e usá-los no contexto de suas próprias culturas, destaca Ceasu (2018). Essa mudança de perspectiva não pode dar-se sem dificuldades.

\section{Um outro olhar para a racionalidade e para a pedagogia: o cenário pós-moderno como chance}

A Pedagogia vê a sua condição estruturante em crise. Aceitar que esse cenário traduz as condições da morte da Pedagogia como campo enunciativo por absoluta incapacidade de sustentar normativamente algum discurso para a educação? Isso significaria sucumbir ao niilismo e, implicaria, por decorrência, reconhecer a morte da própria escola como promessa moderna de formação humanista.

Podemos entender, no entanto, que a pós-modernidade não anuncia outra era, que ela não é outra coisa senão o desdobramento da própria Modernidade, um traço cultural da atual fase do Capitalismo. Concluir que "nada mais resta, nada mais há" seria uma posição demasiado fatalista. A pós-modernidade fica melhor entendida sob o ponto de vista de uma invenção literária (POPOVENIUC, 2017), ou seja, um sentido de conformar uma certa narratividade - plural, antirracionalista, subjetivista, relativista - que tenta, ainda a um modo moderno, porventura, enquadrar, descrever e mapear a difusa situação social que nos assombra. 
Habermas (2000, p. 8) entende que o pensamento pós-moderno tem uma posição ainda transcendental e que permaneceu preso aos "pressupostos de autocompreensão" que ainda são os da Modernidade. Mas não podemos nos confundir. A narrativa pós-moderna nega e relativiza a própria ciência, reduzindo a sua produção discursiva a nuances de mera retórica. Podemos, porém, aprender com o pós-moderno e refletir a partir do que ele nos interpela como limite da razão moderna, da qual ele próprio é originário.

Habermas (2004) também concorda que o ideal de emancipação da Modernidade ainda não foi realizado, que não esgotou, portanto, as suas possibilidades. Não se trata, naturalmente, apenas de obter um pouco de esperança ao "relativizar" o impacto devastador da racionalidade objetivadora e técnica. Se ainda fosse possível, numa nova busca, encontrar nos moldes modernos uma indicação segura e suficientemente válida, sem discussão, dos atos a cumprir, poderíamos nos seduzir com a possibilidade, sempre tentadora, de uma nostalgia restauradora. Impõese diante desse impasse uma vigilância epistemológica mais séria do que isso. Se vivemos uma razão esquecida de si, esse esquecimento seria das suas intenções originais, que foram excessivamente instrumentalizadas, tecnificadas ou “coisificadas", como já haviam apontado Adorno e Horkheimer (1985).

Rosa Nunes (2005), com precisão, destacou que "a racionalidade dominante se escorou no recalcamento da interrogatividade" (p. 98), promovendo a fraqueza da faculdade crítica, uma condição que era fundamental ao pensamento moderno. De um lado já não se distingue entre fato e opinião, mas se não há um acontecimento em si, como já apontou Nietzsche, ainda podemos reconhecer a fecundidade presente em uma pluralidade de sentidos. Podemos recorrer ao resgate da interrogatividade da qual fala Nunes e buscar possibilidades no campo da argumentação, já que não obtivemos êxito somente pelo caminho da demonstração (NUNES, 2005, p. 103).

Para Nunes, seria necessária uma renovação da retórica pós-moderna, aqui entendida como invenção literária, tal como falou Popoveniuc (2017). Essa renovação se daria pelo caminho da argumentação, da interpretação que reconhece a interferência estrutural do sujeito no objeto observado" (NUNES, 2005, p. 34). Isso implicaria a busca de uma leitura descentrada que permita compreender antes de 
“saber" ou de "julgar", como condição de reconstrução hermenêutica. Nunes sinaliza uma nova racionalidade, denominada transcultural (p. 104), que possibilite esclarecimento e compreensão de como sobre jogos de linguagem se podem "edificar pontes entre diferentes formas de vida" (p. 32), uma racionalidade que possibilite "perceber semelhanças básicas naquilo / naqueles que vamos imputando de diferentes" (p. 104).

Os discursos produzidos pela Modernidade sempre aspiraram a ideia de ruptura, de superação da ordem imediatamente anterior qualificada como "tradicional", obscura, carregando uma exigência permanente de mudança, um compromisso constante com o "novo". Nesse sentido, portanto, a mudança erige-se como valor em si, configurando o que Boulnois (2016, p. 325) chamou de um verdadeiro "imperativo cultural", pois "ser moderno é buscar sempre mais modernidade." Segundo o autor, cada momento da história tem a sua própria forma de modernidade" (p. 324). Esse tempo pós-moderno, ao mesmo tempo que aponta falta de esperança, reclama pelo "novo" e indica que há um funcionamento "tradicional" a ser superado, movendo-se, portanto, ainda numa lógica que é tipicamente herdeira da Modernidade.

\section{Perspectivas para a Pedagogia no cenário pós-moderno}

A problemática em pauta neste estudo é a de que há em curso um questionamento sobre as bases possíveis da normatividade de um discurso para a vida social como um todo, mas, de modo específico, para a Pedagogia. Habermas (2004) destaca que vivemos um pluralismo epistêmico, cultural e interpretativo e que essa "multiplicidade de perspectivas" só pode ser minimamente equacionada em "um diálogo abrangente."

Muitas são as narrativas que circulam em busca de legitimidade e falar em narratividade é aceitar que há alguma força no terreno pós-moderno, reconhecer que a força do vivido se impõe sobre qualquer sentido prescritivo prévio. A lógica da narratividade, ou seja, "o modo como os atores conferem sentido às suas ações e prática individuais e grupais", inverte o primado da teoria (prescritiva, legisladora) 
sobre a prática (experiência concreta) e coloca a ação social no centro, como base de qualquer pretensão de legitimidade (MAGALHÃES; STOER, 2007, p. 136).

A Pedagogia da tradição moderna tem um caráter legislador, tal qual os parâmetros científicos e filosóficos que a sustentam. Essa pedagogia legisladora (CAMOZAT'TO, 2015) opera numa crença de que as pessoas possuem uma infinita capacidade de serem influenciadas, moldadas (p. 503). Opera com um "conjunto de saberes e práticas postas em funcionamento para produzir determinados modelos de sujeito" (p. 506), no caso, como já tratamos, o sujeito educado da perspectiva humanista, presente em distintas formações discursivas de cunho pedagógico.

No entanto, com a pós-modernidade, o institucional, o formal, o instituído, o normativo, tudo "faz-se em pedaços", pois “despedaçadas [estão] as suas pretensões de dar conta de aplacar as incertezas, legislando", refere Camozatto (Idem, p. 514). Diante de um cenário de difícil sustentação para uma pedagogia meramente legislativa, poderíamos alinhar argumentos em torno de "pedagogia intérprete", na direção que já trouxemos com Nunes (2005), uma abordagem transcultural sustentada numa perspectiva hermenêutica. Buscar traduzir afirmações produzidas numa tradição pedagógica para que possam ser compreendidas e consideradas em outra. Nessa perspectiva, não estaríamos diante da morte da Pedagogia, mas diante da possibilidade de adequação das expectativas de uma pedagogia universal (a legisladora) para uma pedagogia específica (a intérprete).

Essa perspectiva nos lembra de que ainda somos mais modernos do que se pode supor. A própria pós-modernidade tem mostrado que abriu espaço para novos temas, para olhares menos absolutos, não necessariamente menos críticos, embora certamente menos pretensiosos. Para Ferrero e Torrano (2017, p. 285), se "não há transcendência metafísica e utopia ideológica é uma coisa do passado”, estando perdida a teleologia e suas supostas garantias, "tudo pode ser resolvido agora e aqui, em uma construção dramática que oscila entre realidade e ficção".

A Pedagogia no tempo pós-moderno vive sob o imperativo do tempo presente, ao contrário da Pedagogia Moderna que opera com a qualificação do futuro. Para os autores, o presente complexo abre-se como um horizonte de possibilidades a partir da ideia de "performance" (p. 283), no sentido de que a formação humana 
funcione como uma peça de teatro que encena uma obra aberta, "num processo de construção e reconstrução".

Emerge, portanto, um caminho pedagógico interpretativo que vai sendo encenado no percurso. Transita pelo mundo virtual, pela autoeducação, pelas diferenças, livre de âncoras pesadas e também passa pelos ambientes institucionais. Essa pedagogia intérprete do processo formativo, em constante reafirmação, sempre aberta, não implica, no entanto, cair num relativismo pedagógico. Vivemos em um mundo de muitas referências, nexos de sentido, um mundo "empalavrado", em que "muitas referências textuais" aparecem e é preciso "ler para interpretar os valores que [delas] se destilam” (VILANOU et al. 2018, p. 74, grifo meu).

Nóvoa (2014) analisou o cenário educacional contemporâneo e reforça que "precisamos de vistas largas, de um pensamento que não se feche nem nas fronteiras do imediato, nem na ilusão de um futuro mais-que-perfeito” (p. 171). A escola moderna forjou um projeto de formação ambicioso, "assumiu programa impossível e acreditou que podia cumpri-lo” (p. 176). Porém, resguarda Nóvoa, a escola continua seu trabalho institucional e deveria focar-se na sua tarefa mais importante, a aprendizagem dos seus alunos e alunas.

A escola moderna "desviou-se muitas vezes das tarefas do ensino e da aprendizagem para se dedicar às missões sociais" diversas. Essa "escola transbordante", diz Nóvoa, (2014, p. 176) gerou o alargamento de funções assistenciais e a perda da noção de prioridade. Para o educador português, o passado está inscrito em toda a nossa experiência e o futuro sempre se anuncia na história presente. Nesse sentido, sinaliza três grandes movimentos em curso nesse "futuro presente": o regresso às formas de educação familiar (desescolarização), a definição da educação como um bem privado (mercado da educação) e a importância das novas tecnologias (formas distintas de ensino).

Para Farrero (2014, p. 76) o avanço de modos educativos não formais (autoformativos) e o avanço do caminho de personalização educativa (educação doméstica, por exemplo) é compatível com a posição pós-moderna, em que conta o que tem valor para o indivíduo como interesse próprio. Para ele, faz muito sentido 
pensar uma formação que entrelace processos autoformativos, no sentido de educação permanente buscada pelo próprio sujeito e por ele gerida ao longo da vida, e heteroeducação, ainda com a contribuição da educação formal, mas não necessariamente escolar.

Essa perspectiva pedagógica da qual fala Farrero tem sido conhecida como nomadismo pedagógico, uma espécie de pedagogia pedestre, compatível com a dramaturgia já mencionada, e inspira-se na noção de "homo-viator", o homem que anda, formulada pelo francês Gabriel Marcel (1889-1973), a partir da premissa itinerante do ser humano, tal como o cigano, o andarilho, o fugitivo, o turista, o exilado ou o vagabundo. $\mathrm{Na}$ perspectiva de uma pedagogia pedestre, as práticas pedagógicas nômades permitiriam, no caminhar literal ou na caminhada da experiência, aprender de modo informal e espontâneo: aprender a confiança em si mesmo, aprender no plural, na perspectiva, na ação e também na contemplação.

Cosme e Trindade (2013), por sua vez, sugerem o "paradigma pedagógico comunicacional" para fazer frente aos limites tanto do paradigma da instrução (modelo da Escola Tradicional), como do paradigma da aprendizagem (modelo da Escola Nova). Ainda que partilhem com o modelo da Escola Nova a questão de levar em conta "as singularidades dos alunos e de estimular o seu protagonismo" (p. 43), resguardam o reconhecimento do "patrimônio cultural dito comum" (p. 44) como “fator regulador e catalisador da atividade e do projeto de formação." Isso, segundo os autores, requer uma interlocução qualificada, portanto interpretativa e comunicativa, um eixo pedagógico que aproxima-se do que aqui apontamos como pedagogia intérprete. Os autores buscam ajustar o papel da escola, dos alunos e dos professores de um modo em que todos sejam convocados a tomar posição. Nem a ênfase no mestre explicador, nem a prioridade aos interesses imediatos dos alunos e aos modos de aprender. A escola retomaria a centralidade do conhecimento na formação humana na perspectiva de que o patrimônio cultural é a linha de intersecção pedagógica numa pedagogia em que todos estão ativos.

Há um legado na tradição moderna humanista que não precisa ser subestimado como se vivêssemos um presente sem passado. Se somos herdeiros de uma tradição, podemos muito bem lidar com ela, reinterpretá-la em suas possibilidades de sentido, 
considerar a sua produtividade mediadora frente às necessidades presentes. Do mesmo modo, dispomos de recursos para gerar novas tradições, levando ou não em conta esse repertório novo. Para a ideia de performance, para "atuar" numa obra em permanente construção e reconstrução, quanto mais repertório estiver disponível a esses atores, tanto mais fecundo será o processo criativo e interpretativo.

\section{Considerações quase finais}

No contexto pós-moderno, um enunciado pedagógico não tem mais a força legisladora, se difunde e legitima de maneira mais sutil do que impositiva, gerando uma ação, como já apontado, do tipo “dramatúrgica.” Estará, deste modo, em permanente construção quanto à sua validação.

O trabalho pedagógico de formação humana feito na escola nos impõe reconhecer, no entanto, que não há projeto educativo sem uma teleologia mínima. Mas vemos também que não é mais possível uma teleologia unívoca, à prova de circunstâncias e a salvo da especificidade dos contextos. O trabalho feito na escola com as novas gerações tem a marca de ser um processo intencional, continuado e progressivo, portanto planejado em torno de finalidade mais ou menos explícitas. Porém, numa perspectiva pós-moderna, o trabalho escolar poderá dialogar com outras modalidades formativas, não necessariamente institucionais.

Ora, a Pedagogia contemporânea vê-se com bons desafios para reconfigurar o seu papel diante da escola dos tempos pós-modernos. No caminho que estamos propondo, trata-se de assumir um olhar para as questões pedagógicas numa perspectiva hermenêutico-interpretativa. Significa não renunciar compulsoriamente aos conteúdos da formação humanista moderna, ainda que se considere a fragilidade prática do ideal de universalização dos esquemas explicativos, seja do sujeito ou dos

processos. Também significa compreender que não é possível educar sem um amparo discursivo minimamente compartilhado, uma narrativa pedagógica que faça sentido numa dada comunidade escolar, em torno de um determinado patrimônio cultural e moral “dito comum”, tomando expressão de Cosme e Trindade (2013). 
O processo formativo escolar, ainda que dialogue com espaços e modalidades informais, tem a marca de ser institucional, intencional e planejado. Portanto, a ação pedagógica requer um anteparo, ainda que dramatúrgico e processual. Precisará de constante retomada de suas pretensões de validade em torno do seu suporte metateórico (teses filosóficas que informam concepções de mundo e de função da educação), do seu suporte teórico-cientifico (referências teórico-práticas) e do suporte tecnológico-aplicativo (referências normativas da ação e da prática pedagógica).

Há, no entanto, um desafio de pesquisa a ser aprofundado, que seria a possível reconfiguração discursiva destas categorias estruturantes da Pedagogia em um ambiente pós-moderno. Considerar diferentes narrativas pedagógicas de cunho moderno tendo em vista oferecer alternativas ao trabalho pedagógico de forma reflexiva, ainda que não determinista. Ou, ainda, de que modos os papeis da escola, em particular da escola pública, podem ser reconfigurados em um estatuto pedagógico que permita fazer frente a questões de uma "escola transbordante" em demandas muito mais sociais do que acadêmicas, tal como mencionou Nóvoa.

Vattimo (1992, p. 16) nos lembra que "viver no mundo múltiplo significa fazer experiência de liberdade como oscilação contínua entre pertença e desenraizamento". A condição pós-moderna é inegável, assim como é inegável o empalidecimento de certas expectativas tipicamente modernas. Estas não soam mais do que como arranjos discursivos, narratividades com força sempre relativa. No entanto, a escola continua como uma conquista social importante da era moderna, uma vez que o patrimônio de uma escola obrigatória, portanto com certa universalidade em seu alcance; laica, portanto secularizada e pública, não pode e não deve ser recusado. A escola continua e, ao que tudo indica, continuará como um espaço importante de formação humana, necessitando, porém, ser reinterpretada.

\section{Referências}

ADORNO, T.; HORKHEIMER, M. Dialética do Esclarecimento. Rio de Janeiro: Zahar, 1985.

BOULNOIS, O. ¿Qué hay de nuevo? La Edad Media. Universitas Philosophica, n. 67, v. 33, 321-350, 2016. DOI: https://doi.org/10.11144/Javeriana.uph33-67.qnem 
CEASU, F. Education Seen through the Postmodernity "Grid." Postmodern Openings. Iasi, Romenia, v. 9, n. 1, p. 22-34, jan/abr. 2018. DOI: https://doi.org/10.18662/po/03

CAMOZZATO, V. C. Entre a pedagogia legisladora e as pedagogias intérpretes. Revista Brasileira de Educação, Rio de Janeiro, v. 20 n. 61, p. 501-520, abr.-jun. 2015. DOI: http://dx.doi.org/10.1590/S1413-24782015206111

COSME, A.; TRINDADE, R. Organização e gestão do trabalho pedagógico: perspectivas, questões, desafios e respostas. Porto: Mais, 2013.

EBY, F. História da Educação Moderna. Porto Alegre: Editora Globo, 1970.

FARRERO, J. Presencia de la pedagogía em el ato de caminhar: homo viator, nomadismo y formación. Educación y Cultura en la Sociedad de la Información, Salamanca/Espanha, v. 15, n. 4, p. 56-84, dez. 2014.

FARRERO, J. G.; TORRANO, C. V. Postmodernity and Education. Death of Man and Death of Pedagogy. Espacio, Tiempo y Educación, Salamanca, v. 4, n. 2, p. 273-286, jul/dez. 2017. DOI: http://dx.doi org/10.14516/ete.151

HABERMAS, J. Discurso filosófico da modernidade. Trad. Luiz Repa \& Nascimento. São Paulo: Martins Fontes, 2000.HABERMAS, J. A ética da discussão e a questão da verdade. Trad. Marcelo Cipolla. São Paulo: Martins Fontes, 2004.

KANT, I. Sobre a pedagogia. Trad. Francisco Fontanella. $2^{a}$ ed. Piracicaba, UNIMEP, 1999.

LEMOS, F. O que é um modelo pedagógico? Contribuições filosóficas a um problema de metodologia histórica. Educação, Sociedade e Cultura, Porto/Portugal, n. 51, p. 155-171, 2017.

LÓPEZ, B. G. La teoría de lá educación. Objecto, enfoques e contenidos. Teoría de la Educación. Revista Interuniversitaria. Salamanca/Espanha, n. 14, p. 19-46, 2002.

LYOTARD, J. A condição pós-moderna. Trad. Ricardo Barbosa. $5^{a}$ ed., Rio de Janeiro: José Olympio, 1998.

MAGALHÃES, A; STOER, S. A narrativa das narrativas: um estudo das narrativas educacionais de investigadores docentes na FPCE-UP. Educaşão, Sociedade e Culturas, Porto/Portugal, n. 24, p. 135-154, 2007.

NIETZSCHE, F. Fragmentos póstumos - Volume IV. Trad. Juan Verbal e Juan Llinares. Madrid, Technos, 2006.

NIETZSCHE, F. O nascimento da tragédia, ou helenismo e pessimismo. Trad. J. Guinsburg. $2^{\mathrm{a}}$ ed. São Paulo, Companhia das Letras, 1992.

NÓVOA, A. Educação 2021. Para uma história do futuro. Educação, Sociedade \& Culturas, Porto/Portugal, no 41, p. 171-185, 2014.

NUNES, R. S. Nada entre nós, sem nós: a centralidade da comunicação na obra de Boaventura de Souza Santos. São Paulo: Cortez, 2005. 
POPOVENIUC, B. From Modern Closure to Postmodern Openings. Postmodern Openings, Iasi / Romenia, v. 8, n. 3, p. 6-10, set./dez. 2017. DOI: https://doi.org/10.18662/po/2017.0803.01

SANTOS, B. S. Pela mão de Alice: o social e o político na pós-modernidade. $7^{\text {a }}$ ed. São Paulo: Cortez, 1997.

SAVIANI, D. Pedagogias contra-hegemônicas no Brasil. Ideação - Revista do Centro de Educação e Letras (Foz do Iguaçu), v. 10, n. 2, 2008, p. 11-28.

SAVIANI, D. A Pedagogia Histórico-Crítica. Revista Binacional Brasil Argentina, Vitória da Conquista, v. 3 n. 02, p. 11-36, dez. 2014.

SAVIANI, D. O conceito dialético de mediação na pedagogia histórico-crítica em intermediação com a psicologia histórico-cultural. Germinal: Marxismo e Educação em Debate, Salvador, v. 7, n. 1, jun. 2015, p. 26-43, 2015. DOI: http://dx.doi.org/10.9771/gmed.v7i1.12463

VATTIMO, G. A sociedade transparente. Trad. Hossein Shooja e Isabel Santos. Lisboa: Relógio D’água, 1992.

VILANOU, C. et al. A viabilidade do humanismo pedagógico na Europa pós-moderna. In: LLEIXA, T. et al. [eds.] Educación 2018-2020: retos, tendências y compromissos. Barcelona: IRE-UB, 2018. p. 73-84. 